\title{
DEMOCRACIA CLÁSSICA E MODERNA: DISCUSSÕES SOBRE O CONCEITO NA TEORIA DEMOCRÁTICA ${ }^{1}$
}

\author{
Nayara Fátima Macedo de Medeiros ${ }^{2}$
}

\begin{abstract}
Resumo
O significado do termo "democracia" variou substancialmente ao longo do tempo. Se nas suas origens, democracia estava relacionada à participação direta das pessoas nas decisões públicas, a participação popular foi cedendo cada vez mais espaço a outras preocupações e à alternativa da representação. Argumentou-se, nesse sentido, que a mudança principal teria ocorrido no advento das concepções minimalistas da democracia. Este trabalho pretende mostrar que tal mudança se iniciou antes, em discussões teóricas presentes no pensamento de autores como John Stuart Mill e os federalistas. O problema central aqui analisado é a transformação do conceito de democracia, em que se transfere o foco da participação popular e do princípio de igualdade política para a questão da legitimidade. A análise é feita por meio de uma revisão bibliográfica que considera alguns dos principais expoentes do pensamento político em uma perspectiva histórica contextualizada. Assim, a construção do enquadramento teórico relativo ao conceito de democracia passa por diferentes períodos históricos e contextos. Conclui-se que a mudança no significado de democracia está relacionada principalmente à emergência de novas preocupações com a estabilidade do regime, considerando o contexto histórico em que as discussões tiveram lugar.
\end{abstract}

Palavras-chave: democracia, participação, teoria política.

\begin{abstract}
The meaning of "democracy" has varied substantially over time. Whereas its origins were related to the concept of direct participation in public decisions, the popular participation has been losing ground to other concerns and to representation as an alternative. In this sense, some researchers have argued that the main change took place during the development of the minimalist conceptions of democracy. The present work intends to demonstrate that this change started previously in theoretical discussions on the political thinking of authors such as John Stuart Mill and the federalists. The central problem analyzed here refers to the transformations of the concept of democracy, in which the focus on popular participation and the principle of political equality moved to the question of legitimacy. The analysis is done through a bibliographical research that considers some of the major political thinkers in a historical and contextual perspective. Thus, the building of the conceptual framework regarding democracy passed through different contexts and historical periods. We conclude that the changes the concept of democracy suffered are mainly related to the emergence of concerns about the stability of the regime, considering the historical context in which these discussions took place.
\end{abstract}

Keywords: democracy, participation, political theory.

\section{Resumen}

El significado de la palabra "democracia" cambió sustancialmente con el tiempo. Mientras que sus orígenes estaban relacionados con el concepto de participación directa en las decisiones públicas, la participación popular ha cedido espacio a otras preocupaciones y a la representación como una alternativa. En ese sentido, algunos autores argumentan que el principal cambio ocurrió a lo largo del desarrollo de las concepciones minimalistas de la democracia. Ese trabajo tiene como objetivo demostrar que el cambio empezó previamente en las discusiones teóricas en el pensamiento político de autores como John Stuart Mill y los federalistas. El problema central analizado aquí se refiere a las transformaciones del concepto de democracia, en que se desplaza el foco de atención de la participación popular y del principio de igualdad política a la cuestión de la legitimidad. El análisis es realizado mediante una investigación bibliográfica que considera algunos de los más importantes

\footnotetext{
${ }^{1}$ DOI deste artigo: $10.5380 /$ recp.v6i2.42359.

2 Doutoranda na Universidade de Brasília, é membro do grupo de pesquisa "Democracia e Desigualdades" do Instituto de Ciência Política. E-mail: nayaramcd@gmail.com
} 
autores del pensamiento político en una perspectiva histórica y contextual. Por lo tanto, la construcción del marco teórico atraviesa diferentes contextos y momentos históricos. Llegamos a la conclusión de que los cambios que el concepto de democracia ha sufrido a lo largo del tiempo están relacionados con el surgimiento de nuevas preocupaciones por la estabilidad del régimen, considerando el contexto histórico en el que las discusiones tuvieran lugar.

Palabras-clave: democracia, participación, teoría política.

\section{INTRODUÇÃO ${ }^{3}$}

A origem do termo democracia, na Antiguidade Clássica, aponta a igualdade política como seu princípio norteador. Não por acaso diversos cargos públicos na Grécia eram preenchidos por meio do sorteio, o qual era visto como uma forma de providenciar "chances iguais" para a ocupação desses postos. Por outro lado, as eleições eram vistas como um método oligárquico e consequentemente contrapunham-se ao conceito de democracia (MANIN, 1997, pp. 8-79). Em algum momento da história política ocidental, a lógica se reverteu: a democracia passou a ser associada cada vez mais ao governo representativo, enquanto o ideal de igualdade política cedeu espaço a outros objetivos, como a questão da estabilidade e da legitimidade encarnada no consentimento dos governados.

$\mathrm{Na}$ Ciência Política, esse momento de ruptura geralmente é visto como fruto de um casamento entre duas correntes ideologicamente opostas: a teoria da democracia e o elitismo (ver MIGUEL, 2002, pp. 483-511). Uma consequência disso é que as teorias que se diziam como descritivas dos modelos ocidentais passaram a ser chamadas de "minimalistas", em que se destacava a diminuição do escopo da participação popular em uma crítica efusiva a essas vertentes (ver, por exemplo, PATEMAN, 1992, pp. 20-30). Entretanto, a associação entre democracia e representação e o distanciamento da participação popular são resultados de um mesmo processo histórico que antecede o próprio surgimento de uma concepção minimalista da democracia.

Tal processo demonstra as diversas transformações que o conceito sofreu de acordo com os diferentes contextos nos quais ele esteve inserido. A expressão "democracia" adquiriu tantos significados e combinações institucionais diversas que Robert Dahl afirma que “'democracia' tem significado diferentes coisas para diferentes pessoas em diferentes épocas e lugares" (apud DELLA PORTA, 2013, p.2).

O presente artigo tem como objetivo principal discutir quais foram esses diferentes significados em comparação com essas “diferentes épocas e lugares”. Essa discussão será

\footnotetext{
3 Agradeço aos comentários e sugestões dos pareceristas anônimos. Cabe destacar que qualquer falha ou equívoco é de responsabilidade exclusiva da autora.
} 
feita com base em uma revisão bibliográfica dos debates sobre o regime democrático na teoria política em comparação com seu contexto histórico-social. Isso é feito por meio da análise da construção de um diálogo entre alguns expoentes do pensamento político que se debruçaram sobre a questão.

Traçando desde a Antiguidade Clássica, nas discussões de Aristóteles sobre formas de governo, até debates mais recentes, espera-se analisar como o conceito de democracia variou e quais as consequências dessa variação para os desenhos institucionais adotados no Ocidente. O artigo está estruturado em quatro debates fundamentais na teoria democrática: i. Formas de governo na Antiguidade Clássica; ii. Contrato Social e Legitimidade Democrática; iii. Democracia para John Stuart Mill e os Federalistas; iv. Democracia Minimalista e suas Críticas. Será apresentado brevemente na última seção o estado da arte em relação aos debates mais recentes sobre participação e representação, principalmente no que tange à interação entre os dois conceitos e a relação de ambos com a democracia.

Destarte, é possível traçar uma linha temporal entre essas discussões que mostra uma mudança no foco da concepção de democracia: ao passo que na Antiguidade imperava o princípio de igualdade, a modernidade deslocou essa preocupação para questões de legitimidade e estabilidade. A intenção é discutir como se operou essa mudança e quais as consequências para o regime democrático tal como concebido na contemporaneidade. Essa análise permeia uma discussão dos conceitos de representação e participação em termos da relação entre eles e a interação com a concepção de democracia.

$\mathrm{O}$ argumento exposto neste artigo é que as teorias minimalistas, na verdade, descrevem uma democracia que é resultado de um processo de mudança de foco que teria se iniciado muito antes do surgimento dessas formulações teóricas. Tal mudança refere-se a uma movimentação no debate político, que passou a centralizar na estabilidade do regime.

\section{FORMAS DE GOVERNO NA ANTIGUIDADE CLÁSSICA}

O imaginário em torno do que se entende hoje por democracia foi bastante influenciado pela concepção grega, embora o modelo institucional adotado seja completamente diferente do desenho das instituições atenienses. O modelo grego continha diversos elementos que não estão presentes nos regimes democráticos contemporâneos, como a assembleia popular, o sorteio como método de preenchimento de cargos públicos e a rotatividade das posições de governo (MIGUEL, 2005, pp. 5-30). 
As principais diferenças entre o modelo grego e o contemporâneo encontram-se no papel da participação popular e da representação e na forma com a qual era entendido o princípio de igualdade política. Enquanto, os desenhos institucionais contemporâneos trataram de unir democracia e representação, a interação entre esses dois termos era impensável na Antiguidade Clássica. O modelo ateniense rejeitava as eleições como método democrático, pois elas estavam ligadas diretamente ao conceito de oligarquia, a qual se caracterizava como uma forma de governo completamente distinta da democracia (MANIN, 1997, pp. 8-79).

As eleições constituem-se em uma seleção que visa escolher os mais qualificados, assim como na proposta da oligarquia, a qual pressupõe a escolha de um grupo restrito de pessoas para governar. O mecanismo eleitoral baseia-se, portanto, em uma distinção entre representantes e representados, visto que os primeiros devem se destacar entre os demais devido a uma série de atributos, como riqueza, talento e virtude (MANIN, 1997, pp. 8-79).

A divisão clássica aristotélica trata de seis formas diferentes de governo, que se distinguem por dois critérios: o número de quem governa ${ }^{4}$ e o tipo de interesse (público ou privado). As seis formas recebem o nome de monarquia, aristocracia, politia, tirania, oligarquia e democracia, em que as três últimas se constituem em corrupções das primeiras (ver TILLY, 2006, pp. 5-30). A democracia era o governo dos "muitos" governando em interesse próprio, enquanto a politia seria o governo dos "muitos" governando em prol do interesse público.

A forma positiva mais viável para Aristóteles seria uma combinação entre a oligarquia e a democracia de modo a equilibrar o conflito entre pobres e ricos. Essa combinação seria efetivada por meio da adoção de um "meio termo" entre as disposições extremas dos dois regimes (BOBBIO, 2000, pp. 300-400). A forma com a qual a democracia era vista na Antiguidade clássica distingue-se da perspectiva contemporânea por várias razões.

Primeiramente, há de se destacar que a democracia era uma forma de governo do "povo", ou das massas. As decisões coletivas dependiam, portanto, da participação direta de um largo número de indivíduos - mesmo que excluindo certos segmentos da sociedade, como mulheres e estrangeiros. Em segundo lugar, a democracia era vista como uma forma corrompida de governo e não como um regime positivo como ocorreu no pós-Guerra Fria (BOBBIO, 2000, pp. 300-400). Parte dessa visão justifica-se pelo risco de a assembleia tomar

\footnotetext{
4 O número corresponde a "um", "poucos" e "muitos". Porém, como o número geralmente estava identificado com a classe social, acabava que democracia tornava-se o governo dos pobres e a oligarquia dos ricos (ver Bobbio, 2000).
} 
decisões consideradas como impróprias, como o caso da morte de Sócrates que foi decidida coletivamente. A tomada de decisões por todos, qualificados ou não, era vista como um método arriscado em relação a resultados inadequados.

Por fim, cabe salientar o papel da igualdade política. No caso da Antiguidade Clássica, democracia implicava necessariamente certo grau de igualdade política, mesmo que apenas entre o conjunto restrito de pessoas que podiam ser consideradas como "cidadãs" (ver HELD, 2007 [2006], pp. 1-100).

Nesse contexto, igualdade política não se refere a uma igualdade de resultados, mas de chances em fazer parte das decisões públicas em termos de probabilidade, como mostra a escolha pelo método do sorteio. Quando o ocupante do cargo público é escolhido por sorteio, pode-se dizer que há probabilidades iguais para cada pessoa que quer ocupar tal posto ser escolhida. A igualdade na democracia ateniense não se expressava na distribuição efetiva do poder, mas nas chances iguais de exercê-lo (ver MANIN, 1997, 8-79).

Entretanto, a igualdade política, princípio fundador do conceito de democracia, foi perdendo cada vez mais espaço de devido à predominância de outras prioridades, tais como a concepção de legitimidade, a qual ganha proeminência nas teorias do contrato social.

\section{CONTRATO SOCIAL E LEGITIMIDADE DEMOCRÁTICA}

O que se entende por "contrato social” na teoria política inclui uma série de autores que compartilham de uma mesma lógica de pensamento, embora expressem visões e conteúdos diferentes. Thomas Hobbes, John Locke e Jean-Jacques Rousseau partilham a seguinte fórmula: uma concepção de estado de natureza, uma visão sobre o que seria um estado de guerra e a constituição de um pacto que dá origem à sociedade civil. Entretanto, as diferentes visões que os três apresentam sobre os conceitos de representação e participação são importantes para a compreensão de como se desenvolveu a visão contemporânea de democracia.

Um aspecto central na obra desses três autores é a questão da legitimidade, entendida como aceitação ou consentimento. A legitimidade pode ser entendida como uma subcategoria de dominação, que consistia na obediência de certos grupos a determinado comando. Dessa forma, legitimidade está relacionada a uma obediência voluntária, à aceitação de uma relação de dominação (CROMARTIE, 2003, pp. 93-104). A centralidade desse conceito no contratualismo justifica-se até mesmo pelo contexto histórico em que 
surgiram essas teorias: trata-se do advento do Estado Nacional Moderno, o qual traz consigo a necessidade de justificar e legitimar o poder instaurado.

O Estado Nacional surge em um período marcado por diversos conflitos religiosos e uma estrutura caracterizada pelo policentrismo do poder. $\mathrm{O}$ advento do Estado representa uma concentração de poder em prol da preservação da paz (ver BOBBIO, 1995, pp. 1.0001.190). Na teoria contratualista de forma geral, os súditos aceitam a autoridade do Estado em troca da preservação da ordem. É uma forma de resolução de conflitos: escolhe-se um terceiro - nesse caso, o Estado - para atuar como árbitro. A transferência do poder - dos súditos ao Estado - ocorre, porém, de maneira distinta na perspectiva dos três autores contratualistas.

No caso de Hobbes (2003 [1651], pp. 100-200), essa transferência ocorre por meio de uma total delegação, na qual os súditos abdicam do poder e de sua liberdade em troca da autopreservação promovida por essa terceira parte, cuja função é cumprida pelo Estado. $\mathrm{O}$ estado de natureza, segundo Hobbes, é caracterizado por um estágio de igualdade em termos de disputa e os indivíduos estão sujeitos a suas paixões e aversões. Nesse contexto, o conflito pode ser gerado tanto devido à escassez de recursos quanto à busca pela honra e pela glória (HOEKSTRA, 2007, pp. 109-127).

O estado de natureza hobbesiano é necessariamente um "estado de guerra”, pois há um constante potencial de eclodir uma guerra ${ }^{5}$ devido à igualdade de força e de recursos por parte dos indivíduos e à sujeição deles às suas paixões e medos. Durante o pacto civil, o poder de coerção é transferido de forma que o Estado passa a garantir a paz. As principais consequências dessa visão para uma teoria da representação baseada em Hobbes são dois postulados que estão relacionados: o primeiro é a percepção de que a representação é entendida como delegação; o segundo é a visão do soberano como um ser "mais capaz" que os demais.

Ao passo que não há a obrigação de o Estado ser responsivo aos seus súditos, aparece aqui novamente o princípio da distinção: o "Leviatã" é considerado como o único capaz de manter a ordem e a paz e, por isso, a ele é conferido todo o poder. A legitimidade desse ente todo poderoso encontra-se unicamente no momento da autorização, em que os cidadãos concedem essa concentração de poder na figura do Leviatã ao passo que abdicam da posse de suas ações. O problema da representação é, portanto, reduzido ao momento da autorização (AVRITZER, 2007, p. 446).

\footnotetext{
${ }^{5}$ Sahlins (1983) esclarece que a expressa "guerra de todos contra todos" refere-se a uma disposição geral em vez de uma guerra propriamente dita.
} 
O conceito de representação assume uma roupagem diferente no pensamento de Locke (2006 [1689]). Uma das diferenças cruciais entre o pensamento de Hobbes e o de Locke reside na visão sobre o estado de natureza. Para Locke, o estado de natureza não se constitui necessariamente em um estado de guerra, pois se trata de um estado de cooperação em contraposição à inimizade que caracterizaria o estado de guerra. Entretanto, há um risco inerente de se tornar um estado de guerra devido ao fato de todos serem "igualmente reis" (LOCKE, 2006 [1689], p. 92). O pacto civil é uma forma de manter a preservação da vida, propriedade e bens, evitando que o estado de natureza se transforme em um estado de guerra.

A propriedade privada ocupa um papel central na obra de Locke, visto que se configura no motivo principal pelo qual os homens se associam em sociedade política, a qual apenas pode ser constituída com o consentimento individual. O poder político reside em representantes escolhidos pela população, fundando os pressupostos da democracia representativa. A legitimidade do poder político se encontra na aquiescência individual dos governados em vez da autoridade paterna como desempenhado pelo monarca absolutista (ALVERGA, 2003, pp. 19-50).

Não se trata de um Leviatã que governa, mas um corpo de representantes eleitos pela população. O Poder Legislativo, por outro lado, ganha um enfoque central, pois se constitui no corpo político que deve tomar as decisões. Não há uma delegação total de poder, como no pensamento de Hobbes. Mesmo o poder de tributação, na obra de Locke, deve ser pautado pela anuência dos cidadãos governados, mesmo que esse consentimento seja expresso de forma indireta por meio dos representantes. Nesse contexto, as decisões políticas são tomadas pela regra da maioria, à qual os indivíduos devem se submeter. Em outras palavras, todo indivíduo deve acatar a decisão majoritária (ALVERGA, 2003, pp. 19-50).

Ainda assim, trata-se de uma democracia restrita, primeiramente porque a participação popular se encontra reduzida e em segundo porque a comunidade política é formada exclusivamente por proprietários (ver ALVERGA, 2003, pp. 19-50, 108-150). Esse modelo se diferencia da proposta de Jean-Jacques Rousseau, que se opõe veementemente à agregação numérica de preferências e à propriedade privada.

Para Rousseau (1988 [1755]), a concepção de propriedade privada não teria surgido repentinamente, mas seria consequência de um longo processo que desemboca no último termo do estado de natureza. O estágio inicial desse estado seria caracterizado pelo primeiro sentimento do ser humano, a existência, e a primeira necessidade, que é a conservação de si mesmo. As relações sociais são percebidas a partir do momento em que surgem obstáculos, os quais levam à necessidade de adequação dos seres a si mesmos e de uns com os outros. 
O desaparecimento da igualdade ocorre desde o momento em que o homem precisou do auxílio de outro e que se percebeu ser útil a um possuir provisões para dois, introduzindose a propriedade e fazendo-se necessário o trabalho. Isso significa que a dependência se intercala com a desigualdade quando uns passam a viver à custa de outros. Da propriedade, surgem as primeiras regras da partilha. O estabelecimento político é criado para evitar a desordem, originando a sociedade das leis.

Nesse contexto, o estabelecimento político refere-se ao "falso contrato social", que se constitui em uma legitimação de uma relação de dominação: do pobre pelo rico, que pretende perpetuar a propriedade privada. Os ricos teriam garantido suas próprias posições por meio do convencimento dos pobres em relação à necessidade das instituições políticas para garantir a paz e a justiça (MACFARLANE, 1970, pp. 19-33). Os homens são alienados da própria liberdade, a qual estaria presente somente no estado de natureza.

A alternativa proposta por Rousseau é a construção de uma sociedade que permita o desenvolvimento da personalidade de cada um de seus membros em harmonia com os interesses da comunidade. Nesse caso, as decisões públicas não são tomadas por um conjunto de representantes eleitos, mas por todos os membros da comunidade política em assembleia. Defende-se uma democracia assembleista em que as decisões são alcançadas por meio da "vontade geral", a qual não se trata da agregação das preferências políticas individuais, mas do bem comum (HELD, 2007, pp. 1-100).

Dessa forma, Rousseau se distancia tanto de Hobbes quanto de Locke, pois seu modelo propõe um retorno à democracia direta, em que cidadãos tomariam as decisões eles mesmos sem recorrer a um soberano absoluto ou a um corpo de representantes eleitos. Entretanto, seu modelo encontrava barreiras - como o fato de ser aplicável somente em comunidades muito pequenas - e não teve reflexo imediato no desenho das instituições políticas democráticas.

Ante o exposto, observo que já na época dos contratualistas o foco na teoria política transmutou-se das discussões sobre política e igualdade para a questão de estabilidade. Isso não ocorreu por acaso, tendo em vista o contexto político da Europa de conflitos e múltiplos centros de poder em antecedência ao Estado Nacional. As teorias do Contrato Social surgem em um contexto em que prevalece a necessidade de justificar o poder ao passo que a preocupação com a mitigação dos conflitos se tornava cada vez mais proeminente. A igualdade política cede espaço para a legitimidade, não sem suscitar certa atenção por parte de alguns autores, como mostrado pela obra de Rousseau. 
A ideia de representação ganha espaço no conceito de democracia em contraposição à noção de participação direta popular. Entretanto, a concepção de representação assume diferentes nuances: para Hobbes, há uma delegação total de poderes; para Locke, trata-se de uma seleção de eleitos que, no entanto, devem manter o vínculo com os representados; para Rousseau, representação e democracia são duas noções opostas. A concepção de democracia representativa foi a que permaneceu, influenciando tanto a teoria política com John Stuart Mill e os federalistas, quanto os modelos institucionais contemporâneos, os quais estiveram centrados nas eleições como mecanismo democrático.

\section{DEMOCRACIA PARA JOHN STUART MILL E OS FEDERALISTAS}

Como um dos patronos do liberalismo, a preocupação central de John Stuart Mill (1981 [1859]) consistia em limitar a esfera de atuação de quem detém o poder político de forma a garantir a preservação da liberdade dos indivíduos. Nesse sentido, a liberdade é entendida como a disposição e capacidade em perseguir a própria concepção de bem, contanto que os outros não sejam prejudicados nem impedidos de buscar o próprio bem ${ }^{6}$.

Seguindo essa perspectiva, o único objetivo pelo qual o poder pode ser exercido sobre qualquer membro de uma comunidade civilizada contra sua própria vontade é prevenir prejuízo a outros. Dessa forma, há uma tentativa de justificativa do exercício do poder político, semelhante à fórmula contratualista, porém com ênfase na necessidade de manter a liberdade dos governados em oposição às teorias clássicas do Contrato Social, cujo foco estava no soberano. Não por acaso, o liberalismo clássico enxergava o Estado como um "mal necessário".

Na perspectiva de Mill, o exercício do poder político é necessário para preservar a liberdade dos outros, mas deve ser controlado. A questão do conflito possui novamente um aspecto central, tal como nas teorias do Contrato Social. Em sua reformulação da definição de democracia, Mill (1981 [1859], pp. 1-70) critica a ideia anterior de que democracia seria baseada na identificação de interesses entre governantes e governados. Em um contexto de identificação entre governantes e governados, a nação não precisaria se proteger pois os representantes encorpariam os interesses dela mesma:

O que agora era desejado era que os governantes estivessem identificados com o povo, que seus interesses e vontade fossem os interesses e a

\footnotetext{
${ }^{6}$ Mill (1981 [1859]) considera que os grupos considerados como "descapacitados" - tais como as crianças e os povos que ele chama de bárbaros - são exceções a essa premissa.
} 
vontade da nação. A nação não precisaria ser protegida contra a sua própria vontade. Não havia receio de sua tirania sobre si mesma ${ }^{7}$ (MILL, 1981 [1859], p. 61).

Essa perspectiva sobre a democracia se assemelha à divisão feita por Mansbridge (1983 [1980], pp. 1-36) acerca da democracia unitária e da democracia adversária. Segundo a categorização de Mansbridge, democracia unitária corresponde ao modelo que busca o consenso e o interesse comum, enquanto a democracia adversária é aplicada em um contexto de interesses em constante conflito. A democracia unitária não requer distribuição igualitária do poder, pois os interesses dos representantes são os mesmos dos representados. O problema dessa divisão é que ela legitima a visão de que a democracia adversária seria a única alternativa possível tendo em vista à inviabilidade da democracia unitária, tornando os mecanismos de representação inescapáveis.

De forma semelhante, Mill argumenta que a democracia baseada exclusivamente na identidade entre eleitores e eleitos não precisaria de controle, visto que os interesses do corpo governante corresponderiam aos da nação. Esse tipo de democracia não se efetivaria na prática tendo em vista a inexistência dessa identidade entre quem governa e quem é governado. Nesse caso, a vontade do "povo" corresponde à vontade da maioria (MILL, 1981 [1859], pp. 1-80). É nessa vontade da maioria que reside o risco para Mill, pois eventualmente um sistema sem controles pode se tornar uma "tirania da maioria".

A "tirania da maioria" é também uma preocupação constante nas obras dos federalistas, os quais participaram ativamente dos debates que permearam a construção da Constituição estadunidense. Nessa perspectiva, a democracia era vista como um risco devido ao poder das facções. As facções - entendidas como grupos de indivíduos unidos em determinada causa ou interesse - eram vistas como ameaças porque poderiam comprometer o interesse público (MADISON, 1787, pp. 1-5). Destarte, a formação de uma maioria poderia ser danosa, pois promoveria a defesa de um interesse particularista em detrimento do interesse comum.

Haveria duas formas de mitigar o problema das facções: eliminar suas causas ou controlar seus efeitos. Considerando que eliminar as causas seria inviável para o autor, restaria controlar os efeitos das facções por meio da fragmentação do poder. Madison (1787, p. 4) argumenta que quanto mais partes e interesses, menor a probabilidade de formação de uma maioria que reúna um "motivo comum para invadir os direitos de outros cidadãos".

\footnotetext{
${ }^{7}$ Tradução própria, do original: "What was now wanted was that the rulers should be identified with the people, that their interest and will should be the interest and the will of the nation. The nation did not need to be protected against its own will. There was no fear of its tyrannizing over itself'.
} 
Seguindo essa perspectiva, a alternativa mais adequada para controlar os efeitos das facções seria a república e não a democracia. Para concretizar a solução, o autor argumenta em prol de uma federação:

Assim, fica claro que a mesma vantagem da qual a república dispõe sobre a democracia, em controlar os efeitos da facção, é gozada por uma república maior sobre uma menor e também pela União sobre os Estados que a compõem. Essa vantagem consiste na substituição de representantes cujas visões esclarecidas e sentimentos virtuosos o tornam superior aos preconceitos locais e esquemas de injustiça? Não será negado que a representação da União tem mais chances de possuir essas dotações requeridas. A vantagem consiste na maior segurança provida por maior variedade de partidos, contra o evento de qualquer partido ser capaz de exceder e oprimir o resto? Em um nível igual, a variedade ampliada de partidos no âmbito da União aumenta essa segurança. Isso consiste em maiores obstáculos opostos ao arranjo e conquista dos desejos secretos de uma maioria interessada e injusta? Aqui, novamente, a extensão da União dá o benefício mais palpável ${ }^{8}$ (MADISON, 1787, pp. 4-5).

Madison apresenta uma visão da representação como concepção positiva e que os representantes são vistos como superiores em relação aos representados, tal como pressuposto pelo princípio da distinção discutido por Manin (1997, pp. 1-156). Nesse contexto, a escolha do método eleitoral não se deveu a um argumento de viabilidade, como o senso comum costuma supor, mas de um processo que privilegiou a legitimidade em detrimento da igualdade. A distribuição igualitária de cargos deixava de ser o atributo mais importante do regime enquanto dava-se ênfase maior à necessidade de consentimento por parte das pessoas que estavam sendo governadas.

Por mais que esse "novo" princípio deixasse de lado a questão distributiva, ainda se mostrava mais igualitário do que a fórmula precedente, quando o poder era repassado exclusivamente com base na hereditariedade (MANIN, 1997, pp. 1-156). Esse foi o contexto que permeou a fundação de um dos mais conhecidos regimes democráticos: a Constituição estadunidense, cujo desenho institucional nada tinha a ver com o modelo democrático ateniense, mas teve larga influência sobre o que passamos a entender como democracia contemporânea.

\footnotetext{
8 Tradução própria, do original: "Hence, it clearly appears, that the same advantage which a republic has over a democracy, in controlling the effects of faction, is enjoyed by a large over a small republic,is enjoyed by the Union over the States composing it. Does the advantage consist in the substitution of representatives whose enlightened views and virtuous sentiments render them superior to local prejudices and schemes of injustice? It will not be denied that the representation of the Union will be most likely to possess these requisite endowments. Does it consist in the greater security afforded by a greater variety of parties, against the event of any one party being able to outnumber and oppress the rest? In an equal degree does the increased variety of parties comprised within the Union, increase this security. Does it, in fine, consist in the greater obstacles opposed to the concert and accomplishment of the secret wishes of an unjust and interested majority? Here, again, the extent of the Union gives it the most palpable advantage".
} 
Destaco que a mudança se deu também em decorrência da maior importância que adquiriu o papel do conflito na teoria política. Os contratualistas já mostravam essa preocupação com o conflito e a necessidade de legitimidade do regime, porém a alternativa dada foi o Estado Nacional. Já para Mill, a solução baseava-se em uma democracia representativa, enquanto para os federalistas tratava-se de uma república federalista. Embora apresentem soluções divergentes, é possível encontrar um eixo no pensamento desses autores: a preocupação com a igualdade e distribuição de recursos cedeu, de certa maneira, para a questão do consentimento dos governados.

Desde a origem até conceitos mais recentes, a construção do termo "democracia" esteve estritamente relacionada com um contexto anglo-europeu: do modelo ateniense à formação do Estado Nacional e o contexto conflituoso da Europa, atingindo posteriormente os Estados Unidos em sua independência. Não por acaso uma das correntes mais visadas na teoria democrática é a liberal-pluralista, influenciada largamente pelo modelo estadunidense. Essa corrente trata, na verdade, de um agregado de formulações de diferentes autores, as quais acabaram por ganhar a alcunha de teorias "minimilistas". Tais formulações serão abordadas a seguir.

\section{A DEMOCRACIA MINIMALISTA E SUAS CRÍTICAS}

O que se convencionou denominar de teorias minimalistas da democracia trata-se de um conjunto de abordagens que analisam os regimes democráticos contemporâneos. Entretanto, ao meramente descrever tais regimes, essas concepções acabam trazendo uma formulação do conceito de democracia que se restringe a certas condições institucionais, deixando de fora da análise uma série de fatores relevantes no conceito original de democracia.

O projeto democrático passa a estar associado a uma série de elementos institucionais, como a existência de conjunto de liberdades cidadãs, a competição eleitoral e a multiplicidade de grupos de pressão (ver MIGUEL, 2005, pp. 5-30). A discussão está centrada em aspectos procedimentais, ou seja, quais regras e instituições devem se inserir em um governo para que ele possa ser chamado de “democrático". É o caso da perspectiva de autores como Joseph Schumpeter, Anthony Downs e Robert A. Dahl.

Influenciado por Max Weber, que enxergava a democracia como um sistema de mercado, Schumpeter dizia criticar a doutrina clássica da democracia, na qual o autor 
enquadra perspectivas muito distintas, como, por exemplo, os ideais republicanos, o utilitarismo e o pensamento de Rousseau (ver MIGUEL, 2005, pp. 5-30). De acordo com Schumpeter (1961 [1942], p. 305), o método democrático da doutrina clássica consistia em um "arranjo institucional para se chegar a certas decisões políticas que realizam o bem comum, cabendo ao próprio povo decidir, através da eleição de indivíduos que se reúnem para cumprir-lhe a vontade".

Dessa maneira, a crítica de Schumpeter se funda majoritariamente em dois aspectos da doutrina clássica: a crença na existência de um bem comum e a presunção de uma racionalidade irreal por parte dos indivíduos que compõem o povo. Em contraposição, Schumpeter argumenta que não existe esse bem comum e que os indivíduos possuem uma racionalidade extremamente limitada. Segundo o autor, o patamar de racionalidade dos indivíduos decresceria conforme as questões se distanciassem do interesse privado e se aproximassem do "público". Em situações de presença coletiva, como as "massas", os indivíduos apresentariam ainda mais traços de irracionalidade.

A alternativa proposta por Schumpeter é um sistema em que o povo irracional não tome as decisões diretamente, mas delegue as decisões a um corpo de indivíduos que competiriam pelo poder. O conceito de democracia é reformulado de forma a designar "um sistema institucional, para a tomada de decisões políticas, no qual o indivíduo adquire o poder de decidir mediante uma luta competitiva pelos votos do eleitor" (SCHUMPETER, 1961 [1942], p. 328).

Nota-se que há uma perda considerável em relação ao escopo da participação popular, o que seria alvo de críticas de diversas outras vertentes. Porém, cabe destacar que Schumpeter não estava reinventando o conceito de democracia, mas descrevendo os regimes de sua época. Vale também destacar que parte da perda de espaço da participação na concepção de democracia justifica-se pelo contexto dos regimes totalitários, os quais se caracterizavam por uma larga participação das pessoas mesmo em um contexto de ausência de liberdades fundamentais ${ }^{9}$. O clima geral era de desconfiança em relação à participação popular, sentimento que estaria ligado à presunção de irracionalidade das massas que poderia levar a decisões negativas.

De fato, a racionalidade é um tema que ocupa papel central também no trabalho de Anthony Downs (1999 [1957]), mas com uma nuance distinta de Schumpeter. No seu modelo, o funcionamento da democracia é analisado por meio da dinâmica partidária e

\footnotetext{
${ }^{9}$ Para além dos regimes totalitários, Lee et al (2015) cita uma série de exemplos em que a participação foi utilizada como forma de aumentar desigualdades em detrimento de seu papel democrático.
} 
eleitoral em relação à disputa pelo poder, em que eleitores e governo são vistos como atores racionais no sentido econômico: ambos buscariam a maximização de seus interesses.

Enquanto os membros partidários buscariam a renda, o prestígio e o poder que emanam do cargo público, os eleitores buscariam aumentar o fluxo de benefícios advindo da atividade governamental de acordo com uma estimativa feita em relação aos partidos que estão competindo pelo poder. Desses pressupostos surge a formulação central de Downs (1999 [1957], p. 50) de que os partidos formulariam políticas para ganhar eleições e não o inverso. Novamente a competição é destacada como relevante para a democracia por incentivar os candidatos a formularem políticas de acordo com os interesses dos eleitores a fim de alcançarem o objetivo de se elegerem.

Por outro lado, no pensamento de Dahl, a competição está presente de forma a promover a fragmentação do poder, a qual impediria a formação de uma elite. A estabilidade da democracia estaria garantida, nessas circunstâncias, pela divisão do poder em grupos com interesses distintos (ver MARQUES, 2007, pp. 19-26). Dessa forma, Dahl (2006 [1956], pp. 1-155) substitui o termo "minoria" por "minorias": o que diferenciaria a democracia de uma ditadura seria a existência de minorias no plural, em que a tomada de decisões pelo governo ocorre por meio do apaziguamento de grupos pequenos.

Se Downs restringe sua análise aos partidos e suas relações com os eleitores, Dahl (1962) vai além abordando os grupos de interesse. No pensamento de Dahl, a dispersão dos recursos entre diferentes grupos seria uma barreira à concentração do poder em um grupo só. A fragmentação do poder é um elemento fundamental da poliarquia, a qual é descrita como o regime real mais próximo da democracia de acordo com Dahl (2005 [1972]). Há um retorno às preocupações e alternativas debatidas pelos federalistas em relação a como evitar que o poder de uma facção elimine a liberdade de outros.

Todavia, as "soluções" para os problemas apresentados - ora as dificuldades trazidas pela concepção de bem comum, ora a disputa entre grupos - ainda são restritamente tratadas no âmbito institucional. O que se discute refere-se a regras e determinadas instituições e não ao comportamento ou em como essas regras são socialmente interpretadas. Ademais, a participação popular é relegada a um segundo plano, restringindo-se ao ato de votar e escolher representantes. Há uma desigualdade política evidente entre quem toma diretamente as decisões e aqueles que decidem acerca apenas sobre quais sujeitos tomarão as decisões ${ }^{10}$.

\footnotetext{
${ }^{10} \mathrm{Na}$ realidade, Dahl aborda a questão da desigualdade em várias de suas obras, diferenciando-se dos demais autores dessa corrente liberal-pluralista. Entretanto, seu modelo ainda está centrado em fatores puramente institucionais, como participação de partidos, existência de oposição, etc.
} 
Não por acaso, grande parte das críticas às correntes minimalistas está centrada na redução do papel da participação e no enfoque puramente procedimental. A democracia deliberativa, inspirada no pensamento de Habermas trata de processos comunicativos em termos de como indivíduos podem pressionar o sistema político para atender a suas demandas. Diferentemente da abordagem minimalista, a perspectiva de Habermas está centrada em um aparato diferente das instituições políticas: a esfera pública. Segundo Habermas (2003 [1992], pp. 91-92), a esfera pública é uma rede adequada para a comunicação de conteúdos, tomadas de posições e opiniões, que se reproduzem através do agir comunicativo.

Por meio da esfera pública, as pessoas conseguiriam pressionar o sistema político sem se submeter a uma colonização pela lógica instrumental. Entretanto, essa perspectiva é ainda criticada por restringir a participação à ação de pressão no lugar da promoção da efetiva influência do cidadão e cidadã na arena política formal (ver FARIA, 2000, pp. 47-68). A democracia participativa, por outro lado, aborda como as instituições não políticas interferem no comportamento dos cidadãos e cidadãs de forma a incentivar atitudes mais democráticas em larga escala (ver PATEMAN, 1992, pp. 1-40).

Nesse sentido, a questão é fomentar o comportamento democrático em pequena escala e no dia a dia, em locais como o trabalho, a escola e a família, para que os indivíduos possam agir democraticamente em larga escala, seja nas eleições (no caso das formulações de Mill) ou em outras instituições políticas. A principal função da participação é educativa no sentido do desenvolvimento de capacidades psicológicas necessárias para o exercício da democracia. De forma semelhante, a participação promove o senso de eficácia que os indivíduos acerca de suas próprias ações.

Ressalto que, embora possuam seus próprios limites e desafios, as vertentes deliberacionista e participativa abrangem elementos que vão além do aspecto puramente procedimental. De fato, a igualdade - cerne da concepção original de democracia - foi restringida a um aspecto formal nas abordagens minimalistas: em vez de ser um princípio norteador, passou a designar a regra "um homem, um voto" aplicada a eleições consideradas justas.

Entretanto, as abordagens minimalistas não reinventaram o conceito de democracia sem que houvesse algum processo prévio de transformação. $\mathrm{Na}$ realidade, elas descreveram apenas o resultado de um processo anterior de construção de instituições que passaram a ser vistas como "democráticas". O distanciamento do princípio de igualdade da democracia ocorre antes de Schumpeter e Dahl exporem suas teorias, tendo sido parte dos debates entre 
os federalistas e os anti-federalistas sobre a Constituição estadunidense. A preocupação com a tirania da maioria já estava presente no pensamento de Mill (1981 [1859]), assim como questões relativas à estabilidade do governo eram aspectos centrais.

Todavia, ao assinalar a pretensão de descrever os regimes contemporâneos, tais autores legitimam as instituições existentes sem formular uma crítica ao projeto de democracia que se desenvolveu com base no processo descrito. Ademais, muitos fatores que impactam o funcionamento das instituições políticas descritas ficam de fora da análise. Ao passo que é importante entender as limitações das concepções minimalistas de democracia dentro de seu contexto, aplicar essa perspectiva sem uma visão crítica de seus limites acarreta uma análise demasiada incompleta de um fenômeno político tão complexo quanto a democracia.

\section{DEMOCRACIA HOJE: VELHAS E NOVAS QUESTÕES}

Grande parte dos regimes contemporâneos que se auto intitulam como "democráticos" condiz com as características descritas pelas teorias minimalistas da democracia, i.e. a existência ou não de determinadas instituições, como eleições livres e periódicas, presença de mais de um partido político, liberdade de imprensa, etc. Todavia, como mostram as críticas feitas às concepções minimalistas, a mera existência de tais instituições, em que pese sua importância, não é suficiente para garantir o pleno funcionamento do regime democrático.

Outras formas de participação política além do voto têm ganhado destaque nas experiências práticas contemporâneas e nas discussões no âmbito da teoria política. Protestos em larga escala e novos mecanismos institucionais de participação direta vão além da democracia liberal embora não conflitem necessariamente com a sua existência. Nesse novo contexto, os conceitos de "participação" e "representação" ganham novos questionamentos no que tange à relação entre cidadãos e cidadãs e instituições políticas.

Nesse sentido, discussões sobre democracia têm levantado questões sobre a própria definição desses conceitos e do papel de ambos em um regime democrático. Ao passo que a participação popular esteve historicamente associada à democracia, cresce a preocupação com a possibilidade de a participação se tornar um componente da autoridade (LEE, MCQUARRIE \& WALKER, 2015, pp. 1-23) no sentido de legitimar decisões que realcem 
as desigualdades. Mecanismos de participação direta ${ }^{11}$, os quais tem se ampliado no Brasil por exemplo, não fogem ao debate sobre a possibilidade de a deliberação servir apenas para legitimar decisões tomadas. É preciso distinguir uma participação autônoma e efetiva de um simulacro de participação, como muitas vezes ocorre na prática em ambientes institucionais.

Por outro lado, se representação e participação foram destacadas muitas vezes como conceitos opostos, há autores que deslocam essa polaridade para um caráter complementar (SAWARD, 2006, pp. 297-318; WAMPLER, 2012, pp. 666-682; URBINATI \& WARREN, 2008, pp. 387-412). Representação deixa de significar apenas o voto na urna e passa a abranger outros elementos que abordam o processo mútuo de construção de representantes e representados (ver SAWARD, 2006, pp. 297-318). A questão aqui está centrada em uma "representação democrática".

Essas discussões realçam a importância de discutir como elementos além das "regras do jogo" afetam a capacidade das pessoas participarem efetivamente em uma democracia. Uma vez entendida como distribuição igualitária de poder político, a democracia não pode ser explicada exclusivamente pela existência ou falta de determinadas instituições. Há outros fatores além das regras formais que incidem sobre a capacidade de intervenção de cidadãs e cidadãos ordinários nas decisões públicas. Variáveis como status, posição social, renda/riqueza, raça e gênero influenciam a capacidade que as pessoas possuem de se expressarem politicamente e principalmente de fazer com que suas opiniões e perspectivas "sejam ouvidas".

Caminhamos, portanto, para o debate dos requisitos da "participação autônoma" e suas possibilidades em um contexto marcado por grandes assimetrias de recursos e poder.

\section{CONSIDERAÇÕES FINAIS}

A origem do termo democracia esteve intrinsecamente ligada a um ideal de igualdade política. Na Grécia Antiga, esse ideal foi projetado nas instituições políticas de forma a promover a probabilidade igual dos membros da comunidade política em ocupar cargos públicos. Pressupunha-se que os cidadãos tinham oportunidades iguais de participar ativamente da política, seja por meio da assembleia ou da ocupação de cargos no governo.

\footnotetext{
${ }^{11}$ Descrevo aqui como "mecanismos de participação direta" iniciativas que tem se expandido pelo mundo, como Conselhos de Políticas Públicas e o Orçamento Participativo. Embora sejam iniciativas de cunho deliberativo em vez de participativo no sentido da teoria democrática devido à falta de um elemento impositivo, chamo de "participação direta" por permitirem a atuação direta de cidadãos e cidadãs que não são políticos profissionais.
} 
Mesmo que esse ideal não tenha se concretizado plenamente, pois havia o surgimento de lideranças nas assembleias e nem todos participavam ativamente da política, o imaginário em torno do termo "democracia" permaneceu centralizado na ideia de "governo do povo". Todavia, os mecanismos pelos quais essa concepção foi operacionalizada se distanciaram substancialmente do modelo grego. A resposta tradicional dada pela teoria política apontava que a mudança ocorrera com o surgimento das concepções minimalistas da democracia e o casamento entre democracia e elitismo, os quais eram originalmente contrapostos.

De fato, o que se convencionou chamar de democracia minimalista reduziu a participação popular a uma mera escolha do corpo governante. Entretanto, essa perspectiva não reinventou o conceito de democracia a partir de uma "folha em branco", mas foi resultado de um processo anterior: o da substituição da preocupação com a igualdade pelo foco na estabilidade. As correntes minimalistas, expostas pelo pensamento de autores como Schumpeter, Downs e Dahl descreveram regimes contemporâneos que foram fruto de processos históricos específicos, em especial os debates que deram origem à Constituição estadunidense tal como é atualmente conhecida.

A igualdade perdeu espaço para a preocupação com o conflito e consequentemente a estabilidade do regime. As teorias do Contrato Social expressavam essas questões em uma tentativa de justificar o aparato político centralizado que ali nascia. A mudança de foco para o conflito e a estabilidade pertence a um contexto específico: o do surgimento dos Estados Nacionais e, posteriormente, ao embate entre federalistas e anti-federalistas. O conceito de representação ganha proeminência em detrimento da concepção de participação e de igualdade política.

Vale destacar, porém, que mesmo as correntes minimalistas não abandonaram por completo o ideal de igualdade política. A sentença "um homem, um voto" traz implicitamente a ideia de responsividade igualitária: ao indicar que uma pessoa corresponde a um voto, assinala-se que todos os membros da comunidade política possuem o mesmo "peso" nas decisões públicas. Entretanto, essas concepções acabam por negligenciar o peso de outros fatores, tais como o aspecto econômico ${ }^{12}$ e as desigualdades de gênero e raça, que incidem na capacidade que os eleitores dispõem de influenciar efetivamente as decisões políticas.

Ademais, ao centralizar a discussão meramente nas instituições e regras de funcionamento, corre-se o risco de considerar as eleições como suprassumo da democracia.

12 Com exceção de Dahl (1985). 
Sabemos que, na realidade, isso não acontece. As eleições - por mais que sejam consideradas atualmente como método democrático - constituem-se um meio originalmente oligárquico. Por meio das eleições, tenta-se selecionar os "melhores", ou os mais capacitados para governar. Sobretudo, elas são uma forma extremamente limitada de participação, pois o voto não permite um alto controle sobre a ação dos representantes, nem garante que eles seguirão a vontade dos eleitores.

O voto por si só também não permite que cidadãos e cidadãs interfiram diretamente na política, concedendo-lhes um papel secundário em um regime que teoricamente deveria ser o governo deles. Não por acaso, as concepções minimalistas e o pensamento liberalpluralista em geral foram alvos de diversas críticas, advindas de diferentes correntes da teoria política. Esses outros modelos estão centrados em como aumentar o escopo da participação popular, fomentar o diálogo na esfera pública de forma a pressionar as instituições políticas e construir um conceito mais substantivo de cidadania.

O que se tentou mostrar aqui é que todos esses modelos de democracia foram consequências de processos históricos específicos. As concepções minimalistas apresentam uma perspectiva que não está desvinculada do próprio contexto em que surgiu - a contraposição ao totalitarismo e a emergência de regimes democráticos contemporâneos nem de um processo iniciado antes desde as primeiras preocupações com a estabilidade dos governos. De forma semelhante, o retorno da participação se insere em um contexto de ascensão de novos movimentos sociais e da resultante esperança de que as pessoas passem efetivamente a fazer parte da política.

Isso não significa, porém, que a relação entre realidade e teoria política seja unidirecional: ambas se afetam mutuamente, como mostra a influência dos debates entre federalistas e anti-federalistas no desenho do governo estadunidense. Entender como essa confluência ocorre e como acontece a construção dos conceitos que utilizamos é fundamental para propor avanços na teoria política.

Em um mundo em que se nota cada vez mais o crescimento das desigualdades, não é surpresa que esse se torne um tema mais explorado pela teoria política em futuros trabalhos. Assim, no que tange ao conceito de democracia, não se trata de descartar o debate sobre estabilidade, mas de retomar as discussões sobre participação popular e igualdade de modo a construir um conceito substantivo e não apenas um mero simulacro sem nenhuma relação com o ideal originalmente projetado. 
MEDEIROS, Nayara Fátima Macedo de. Democracia clássica e moderna: discussões sobre o conceito na Teoria Democrática.

\section{REFERÊNCIAS}

ALVERGA, C. F. R. P. 2003. Democracia Representativa e Democracia Participativa no Pensamento Político de Locke e Rousseau. Dissertação de mestrado apresentada ao Instituto de Ciência Política da Universidade de Brasília.

AVRITZER, L. 2007. Sociedade civil, instituições participativas e representação: da autorização à legitimidade da ação. DADOS - Revista de Ciências Sociais. Rio de Janeiro, v. 50, n. 3, p. 443-464.

BOBBIO, N. 1995. Dicionário de Política (A-K). Brasília: Editora Universidade de Brasília. . 2000. Teoria Geral da Política: A Filosofia Política e as Lições dos Clássicos. Rio de Janeiro: Elsevier.

CROMARTIE, A. 2003. Legitimacy. In: BELLAMY, R.; MASON, A. Political Concepts. Nova York: Manchester University Press.

DELLA PORTA, D. 2013. Can democracy be saved? Cambridge: Polity.

DAHL, R. 2006 [1956]. A Preface to Democratic Theory. Chicago: University of Chicago Press. 1962. Who Governs? Democracy and Power in an American City. New Haven: Yale University Press. 2005 [1972]. Poliarquia: Participação e Oposição. Tradução de Celso Mauro Paciornik. São Paulo: Editora da Universidade de São Paulo.

1985. A Preface to Economic Democracy. Berkeley e Los Angeles: University of California Press.

DOWNS, A. 1999 [1957]. Uma teoria econômica da democracia. Tradução de Sandra Guardini Teixeira Vasconcelos. São Paulo: Editora da Universidade de São Paulo.

FARIA, C. F. 2000. Democracia deliberativa: Habermas, Cohen e Bohman. Lua Nova, no 50, São Paulo, pp. 47-68.

HABERMAS, J. 2003 [1992]. Direito e democracia: entre facticidade e validade. v. II. 2 ed. Rio de Janeiro: Tempo Brasileiro.

HELD, D. 2007 [2006]. Modelos de democracia. Tradução de María Hernández. Madrid: Alianza, Terceira Edição.

HOBBES, T. 2003 [1651]. Leviatã. São Paulo: Martin Claret. 
HOEKSTRA, K. 2007. Hobbes on the Natural Condition of Mankind. In: SPRINGBORG, P. (editor). The Cambridge Companion to Hobbes's Leviathan, Cambridge: Cambridge University Press.

LEE, C. W. ; MCQUARRIE, M. e WALKER, E. T. (Eds.). 2015. Democratizing inequalities: dilemmas of the new public participation. New York: New York University.

LOCKE, J. 2006 [1689]. Segundo tratado sobre o governo civil. Martin Claret.

MACFARLANE, L. J. 1970. Teoria Política Moderna. Brasília: Editora Universidade de Brasília. MADISON, J. 1787. Federalist papers: FEDERALIST No. 10.

MANIN, B. 1997. The principles of representative government. Cambridge: Cambridge University Press.

MANSBRIDGE, J. 1983 [1980]. Beyond adversary democracy. Chicago: Chicago University.

MARQUES, D. 2007. Democracia e ciências sociais no Brasil (1985-2005). Dissertação de mestrado apresentada ao Instituto de Ciência Política da Universidade de Brasília.

MIGUEL, L. F. 2002. A Democracia Domesticada: As Bases Antidemocráticas do Pensamento Democrático Contemporâneo. DADOS - Revista de Ciência Sociais, Rio de Janeiro, Vol 45, n³, pp. 483-511.

2005. Teoria Democrática Atual: Esboço de Mapeamento. Em: Revista Brasileira de Informação Bibliográfica em Ciências Sociais, no 59. São Paulo: Editora da Revista BIB, p. 5-42.

MILL, J. S. 1981 [1859]. On Liberty. Harmondsworth: Penguin.

PATEMAN, C. 1992. Participação e teoria democrática. Rio de Janeiro: Paz e Terra.

ROUSSEAU, J. 1988 [1755]. Discurso sobre a origem e os fundamentos da desigualdade entre os homens. São Paulo: Nova Cultural.

SAWARD, M. 2006. The Representative Claim. Contemporary Political Theory, 5, p. 297-318.

SCHUMPETER, J. 1961. Capitalismo, Socialismo e Democracia. Rio de Janeiro: Editora Fundo de Cultura.

TILLY, C. Regimes and repertoires. Estados Unidos: Chicago University Press, 2006.

URBINATI, N.; WARREN, M. E. 2008. The concept of representation in contemporary democratic theory. Annual Review of Political Science. n. 11, p. 387-412. 
MEDEIROS, Nayara Fátima Macedo de. Democracia clássica e moderna: discussões sobre o conceito na Teoria Democrática.

WAMPLER, B. 2012. Participation, representation, and social justice: using participatory governance to transform representative democracy. Polity, v. 44, n. 4, p. 666-682. 